\title{
A Fourier transform-ion cyclotron resonance study of steric effects on proton transfer reactions of polyalkyl benzenes*
}

\author{
Heinz-Hermann Büker and Hans-Friedrich Grützmacher ${ }^{1}$ \\ Fakultät für Chemie, Universität Bielefeld, W-4800 Bielefeld (Germany)
}

(Received 21 February 1991)

\begin{abstract}
The rates of deprotonation, $\mathrm{MH}^{+}+\mathrm{B} \rightarrow \mathrm{M}+\mathrm{BH}^{+}(\mathbf{M}=1,2)$, and the rates of protonation, $\mathrm{M}+\mathrm{BH}^{+} \rightarrow \mathrm{MH}^{+}+\mathrm{B}(\mathrm{M}=2,3,4)$, have been measured by Fourier transform-ion cyclotron resonance (FT-ICR) spectrometry for the increasingly sterically crowded alkyl benzenes ethylbenzene, 1; 1,3,5trimethylbenzene (mesitylene), 2; 3,5-di-( $t$-butyl)toluene, 3; 1,3,5-tri( $t$-butyl) benzene, 4 ; and a series of $n$-bases $B$. In addition, the gas phase basicities of 3 and 4 were determined by proton transfer equilibrium measurements using FT-ICR.

The efficiencies of deprotonation and protonation are always large $(>50 \%)$ for exoergic reactions and increase with increasing exoergicity, but never reach unit efficiency. For each of the alkylated benzenes 1-4 the efficiency decreases steeply at the border between exoergic and endoergic reactions. This is the "normal" behaviour of proton transfer reactions and shows the absence of steric effects for proton transfer to and from alkylated benzenes even in the case of $\mathbf{3}$ and $\mathbf{4}$ substituted by bulky $t$-butyl groups, and is in complete contrast to the behaviour of $t$-butylated pyridines. This difference is explained by different geometries of the transition state for the proton transfer reactions in the case of the alkylated pyridines and alkylated benzenes, and by the critical role of $\pi$-complexes in proton transfer reactions of benzene derivatives.
\end{abstract}

\section{INTRODUCTION}

Gas phase basicities (GB) and proton affinities (PA) of organic compounds are determined by measuring the equilibrium constants of proton transfer [1], by the dissociation of proton bound mixed dimers [2], and by the method of bracketing [3] respectively. In bracketing, the efficiency of a proton transfer between the compound investigated and several bases of known gas phase basicities is determined. The efficiency is predicted to be high for exoergic proton transfer reactions and small for endoergic reactions. This was derived as a general rule from the behaviour of $n$-bases with lone electron pairs as basic centres [4], and usually this rule is assumed to hold for $\pi$-bases also [5],

* Dedicated to Professor Paul Kebarle on the occasion of his 65th birthday.

1 Author to whom correspondence should be addressed. 
although these bases probably react over a double well potential energy surface $[6,7]$.

It is important to know whether the efficiency (eff.) of proton transfer depends not only on the free reaction enthalpy, $\Delta G_{\mathrm{r}}$, of a reaction but is also influenced by steric effects exhibited by the structural complexity of large organic molecules. A test case for such steric effects would be appropriately substituted aromatic $\pi$-bases. Arenium ions, i.e. protonated aromatic compounds, are intermediates of electrophilic aromatic substitutions, and their deprotonation is the final step of these reactions. Cacace [8] has concluded from the results of his extensive studies of the electrophilic aromatic substitution in the gas phase that the deprotonation of arenium ions is sterically hindered by alkyl substituents at the ring. Steric effects of aromatic n-bases have been also studied by Houriet and Rolli [9a] using 2,6-di-( $t$-butyl)pyridine as a model compound. Compared with the unsubstituted pyridine, this compound shows striking effects on the efficiency of protonation as a function of $\Delta G_{\text {prot }}$. As for pyridine, unit efficiency is observed for strongly exoergic protonation. However, the abrupt decline in reactivity usually indicating the border between exoergic and endoergic proton transfer occurs already with reactions still exoergic by about $25 \mathrm{~kJ} \mathrm{~mol}^{-1}$. The authors concluded that steric effects caused by the $t$-butyl groups result in an activation barrier and hinder the efficiency of protonation of 2,6-di- $(t$-butyl $)$ pyridine relative to pyridine. Recently, Meot-Ner (Mautner) and Smith [9b] have outlined the importance of entropy barriers for a proton transfer between sterically hindered pyridines. By their model, the proton transfer reactions proceed through locked-rotor, low-entropy intermediates for sterically hindered, $t$-butyl substituted pyridines. The slow kinetics are described by a complexswitching Rice-Ramsperger-Kassel-Marcus model that allows several complexes to control the proton transfer rate: a series of loose complexes at the initial stage of the reaction, a locked-rotor tight complex occurring on the reaction coordinate before the hydrogen-bonded complex, and a complex located at the central energy barrier of the proton transfer reaction [ $9 \mathrm{~b}]$. Thus it is clear that steric effects influence the rates of exothermic proton transfers, and the application of the bracketing technique may give erroneous gas phase basicities of sterically crowded bases without special care being taken to recognize these steric effects.

We are interested in structural effects on the proton transfer reactions and the proton affinity of certain large organic molecules containing benzene rings in special orientations. An interesting example is provided by macrocyclic cyclophanes [10]. These compounds are difficult to study by the gas phase equilibrium technique because of their low volatility. Although the protonated species are easily generated by chemical ionization, it is not known whether one has to take into account steric effects on the efficiency of 
deprotonation which would make the bracketing invalid for the determination of the gas phase basicity. Hence, a systematic study of steric effects on the deprotonation of arenium ions is needed.

In the present work we have determined the rates of proton transfer between the increasingly sterically crowded aromatic compounds ethylbenzene, 1; 1,3,5-trimethylbenzene (mesitylene), 2; 3,5-di-( $t$-butyl)toluene, 3; and $1,3,5$-tri-( $t$-butyl)benzene, 4 as $\pi$-bases and a variety of $n$-bases by ICR as a test for the occurrence of steric effects on the proton transfer reactions of heavily alkylated benzenes. While these effects are not expected for 1 and probably not for 2 , the $t$-butylated benzenes 3 and 4 are counterparts of 2,6-di-( $t$-butyl)pyridine and may exhibit steric effects on the rates of protonation.

\section{EXPERIMENTAL}

The experiments were performed with an ICR spectrometer Bruker CMS $47 \mathrm{X}$ equipped with an external ion source [11]. This instrumental configuration is particularly well suited for the bracketing technique, because the protonated aromatic compound is formed outside the ICR cell, and the neutral phase of the ICR cell consists of essentially only one component, the reference base. Hence, any interference by a back reaction after proton transfer is excluded. In the present experiments, the rate of protonation of $M$ with $\mathrm{BH}^{+}$and/or the rate of deprotonation of $\mathrm{MH}^{+}$with $\mathrm{B}$ were measured for the alkyl aromatic compounds $\mathbf{M}$ and the $\mathrm{n}$-bases $\mathrm{B}$. The protonated compounds $\mathrm{MH}^{+}$or $\mathrm{BH}^{+}$were generated by chemical ionization $(\mathrm{CI})$ (methane) in the external ion source and transferred into the ICR cell containing either neutral B or M. After isolation of the protonated species by broad band ejection [12] and by "single shots" [12], argon was pulsed into the ICR cell by a pulsed magnetic valve. After half a second pumping time, mass spectra were acquired after various reaction times. The decrease of $\log \left[\mathrm{MH}^{+}\right]$ or $\log \left[\mathrm{BH}^{+}\right]$with the reaction time is linear for the collisionally deactivated ions. The expcrimental pseudo-first order rate constants, $k_{\exp }$, were obtained from the slope of the linear portion of the logarithmic plots for different pressures of $\mathrm{B}$ or $\mathrm{M}$. The bimolecular rate constant, $k$, was determined by plotting $k_{\exp }$ versus the concentration [B] or [M] for $T=300 \mathrm{~K}$.

The concentration of the neutrals was determined from the pressure measured by the ionization gauge located in the high vacuum pumping line of the ICR cell housing. The ionization gauge was calibrated with the reference reaction $\mathrm{CH}_{4}^{+}+\mathrm{CH}_{4} \rightarrow \mathrm{CH}_{5}^{+}+\mathrm{CH}_{3}$ using the value of $k=11.7 \times 10^{-10} \mathrm{~cm}^{3}$ molecule ${ }^{-1} \mathrm{~s}^{-1}$ as its rate constant [13]. The relative ionization cross-sections, $\sigma$ [14], for the pressure measurement of the neutrals were estimated from the 
TABLE 1

Deprotonation of protonated alkyl benzenes $\mathrm{MH}^{+}$by $\mathrm{B}$

\begin{tabular}{llllllr}
\hline $\mathbf{M}^{\mathrm{a}}$ & $\mathrm{B}$ & $\mathrm{GB}(\mathrm{B})^{\mathrm{b}}$ & $k^{\mathrm{c}}$ & $k_{\mathrm{ADO}}$ & eff. $(\%)$ & $\Delta G_{\mathrm{r}}^{\mathrm{b}}$ \\
\hline 1 & $\mathrm{C}_{2} \mathrm{H}_{5} \mathrm{COC}_{2} \mathrm{H}_{5}$ & 810 & 15.1 & 18.0 & 84 & -41 \\
& $\mathrm{CH}_{3} \mathrm{COCH}_{3}$ & 790 & 17.2 & 19.7 & 87 & -21 \\
& $\mathrm{HCO}_{2} \mathrm{C}_{2} \mathrm{H}_{5}$ & 775 & 10.0 & 14.2 & 70 & -6 \\
& $n-\mathrm{C}_{3} \mathrm{H}_{7} \mathrm{CHO}$ & 769 & 4.55 & 18.9 & 24 & 0 \\
& $\mathrm{CH}_{2}=\mathrm{CHCN}$ & 761 & 0.68 & 23.4 & 3 & +8 \\
& & & & & & \\
& $\mathrm{HCON}\left(\mathrm{CH}_{3}\right)_{2}$ & 852 & 21.9 & 22.3 & 98 & -42 \\
& $\left(i-\mathrm{C}_{3} \mathrm{H}_{7}\right)_{2} \mathrm{O}$ & 830 & 10.3 & 12.7 & 80 & -20 \\
& $\mathrm{CH}_{3} \mathrm{OC} \mathrm{H}_{4} \mathrm{OCH}$ & 810 & 6.66 & 10.0 & 67 & -9 \\
& $\left(\mathrm{C}_{2} \mathrm{H}_{5}\right)_{2} \mathrm{CO}$ & 810 & 2.55 & 17.8 & 14 & 0 \\
& $\mathrm{CH}_{3} \mathrm{CH}=\mathrm{CHCHO}$ & 803 & 0.91 & 22.4 & 4 & +7 \\
\hline
\end{tabular}

a $\mathrm{GB}(1)=769 \mathrm{~kJ} \mathrm{~mol}^{-1}, \mathrm{~GB}(2)=810 \mathrm{~kJ} \mathrm{~mol}^{-1}$.

b $\mathrm{kJ} \mathrm{mol}^{-1}$.

c $\times 10^{-10} \mathrm{~cm}^{3}$ molecule ${ }^{-1} \mathrm{~s}^{-1}$.

polarizabilities, $\alpha$, calculated from atomic polarizabilities by the method of Miller and Savchik [15].

The GB of many alkyl benzenes have already been obtained by the equilibrium method [16]. However, the GB of 3 and 4 are not known and have been determined in this work by measuring the proton transfer equilibria $(T=300 \mathrm{~K})$ with ammonia $\left(p\left(\mathrm{NH}_{3}\right)=2.4 \times 10^{-7} \mathrm{mbar}, p(3)=0.25 \times\right.$ $\left.10^{-7} \mathrm{mbar}\right)$ and $\mathrm{N}$-methylformamide $\left(p\left(\mathrm{HCONHCH}_{3}\right)=2.1 \times 10^{-7} \mathrm{mbar}\right.$, $p(4)=0.32 \times 10^{-7} \mathrm{mbar}$ ) respectively. The resulting gas phase basicities are $\mathrm{GB}(3)=825 \pm 2 \mathrm{~kJ} \mathrm{~mol}^{-1}$ and $\mathrm{GB}(4)=830 \pm 2 \mathrm{~kJ} \mathrm{~mol}^{-1}$.

\section{RESULTS AND DISCUSSION}

Tables 1 and 2 summarize the results for the proton transfer reactions of the alkyl aromatic compounds 1-4. By definition, the reaction efficiencies (eff.) correspond to $k / k_{\mathrm{c}}$. The collisional rate constant $k_{\mathrm{c}}$ is approximated by the rate constant deduced from the average dipole orientation model, $k_{\mathrm{ADO}}$ [17].

The results for the deprotonation of protonated 1 and 2 are given in Table 1. The corresponding measurements for the $t$-butylated compounds 3 and 4 could not be performed because the corresponding $\mathrm{MH}^{+}$ions were formed only with very low intensities in the CI source. Surprisingly, and in contrast to 1 and 2 , the compounds 3 and 4 yield mainly radical cations $\mathbf{M}^{++}$ instead of $\mathrm{MH}^{+}$under a variety of $\mathrm{CI}$ conditions. The formation of radical cations instead of arenium ions during $\mathrm{CI}$ experiments with aromatic compounds has been observed before [18]. However, all reasonable reactions 
TABLE 2

Protonation of alkyl benzenes $\mathrm{M}$ by $\mathrm{BH}^{+}$

\begin{tabular}{|c|c|c|c|c|c|c|}
\hline $\mathbf{M}^{\mathrm{a}}$ & B & $\mathrm{GB}(\mathrm{B})^{\mathrm{b}}$ & $k^{\mathrm{c}}$ & $k_{\mathrm{ADO}}$ & eff. $(\%)$ & $\Delta G_{r}^{\mathbf{b}}$ \\
\hline \multirow[t]{5}{*}{2} & $\mathrm{CH}_{3} \mathrm{CN}$ & 756 & 11.2 & 16.5 & 68 & -54 \\
\hline & $\mathrm{HCO}_{2} \mathrm{C}_{2} \mathrm{H}_{5}$ & 775 & 10.7 & 13.5 & 79 & -35 \\
\hline & $\mathrm{CH}_{3} \mathrm{CH}=\mathrm{CHCHO}$ & 803 & 8.5 & 13.8 & 62 & -7 \\
\hline & $\left(\mathrm{C}_{2} \mathrm{H}_{5}\right)_{2} \mathrm{CO}$ & 810 & 5.5 & 12.9 & 43 & 0 \\
\hline & $\mathrm{NH}_{3}$ & 818 & 0.7 & 23.2 & 3 & +8 \\
\hline \multirow[t]{12}{*}{3} & $\mathrm{H}_{2} \mathrm{O}$ & 665 & 27.1 & 29.2 & 93 & -160 \\
\hline & $\mathrm{CH}_{3} \mathrm{OH}$ & 728 & 18.2 & 22.8 & 80 & -97 \\
\hline & $\mathrm{CH}_{3} \mathrm{CN}$ & 756 & 15.1 & 20.6 & 73 & -69 \\
\hline & $\mathrm{HCO}_{2} \mathrm{C}_{2} \mathrm{H}_{5}$ & 775 & 14.3 & 16.4 & 87 & -50 \\
\hline & $\mathrm{CH}_{3} \mathrm{COCH}_{3}$ & 790 & 14.2 & 18.0 & 79 & -35 \\
\hline & $\mathrm{CH}_{3} \mathrm{CH}=\mathrm{CHCHO}$ & 803 & 9.80 & 16.8 & 58 & -22 \\
\hline & $\left(\mathrm{C}_{2} \mathrm{H}_{5}\right)_{2} \mathrm{CO}$ & 810 & 7.93 & 15.6 & 51 & -15 \\
\hline & $\mathrm{NH}_{3}$ & 818 & 17.8 & 29.9 & 59 & -7 \\
\hline & $\mathrm{C}_{6} \mathrm{H}_{5} \mathrm{CO}_{2} \mathrm{CH}_{3}$ & 820 & 6.70 & 13.4 & 50 & -5 \\
\hline & $\mathrm{HCONHCH}_{3}$ & 828 & 1.25 & 17.9 & 7 & +3 \\
\hline & $3-\mathrm{FC}_{6} \mathrm{H}_{4} \mathrm{NH}_{2}$ & 833 & 0.31 & 14.3 & 2 & +8 \\
\hline & $4-\mathrm{FC}_{6} \mathrm{H}_{4} \mathrm{NH}_{2}$ & 838 & 0.44 & 14.3 & 3 & +13 \\
\hline \multirow[t]{7}{*}{4} & $\mathrm{CH}_{3} \mathrm{OH}$ & 728 & 23.8 & 24.8 & 96 & -102 \\
\hline & $\left(\mathrm{C}_{2} \mathrm{H}_{5}\right)_{2} \mathrm{O}$ & 805 & 14.4 & 17.6 & 82 & -25 \\
\hline & $\mathrm{C}_{2} \mathrm{H}_{5} \mathrm{COC}_{2} \mathrm{H}_{5}$ & 810 & 15.0 & 16.7 & 89 & -20 \\
\hline & $\mathrm{C}_{6} \mathrm{H}_{5} \mathrm{CO}_{2} \mathrm{CH}_{3}$ & 820 & 11.1 & 14.2 & 79 & -10 \\
\hline & $\mathrm{HCONHCH}_{3}$ & 828 & 9.40 & 19.2 & 49 & -2 \\
\hline & $3-\mathrm{FC}_{6} \mathrm{H}_{4} \mathrm{NH}_{2}$ & 833 & 0.26 & 15.2 & 2 & +3 \\
\hline & 4- $\mathrm{FC}_{6} \mathrm{H}_{4} \mathrm{NH}_{2}$ & 838 & 0.43 & 15.2 & 3 & +8 \\
\hline
\end{tabular}

a $\mathrm{GB}(2)=810 \mathrm{~kJ} \mathrm{~mol}^{-1}, \mathrm{~GB}(3)=825 \pm 2 \mathrm{~kJ} \mathrm{~mol}^{-1}, \mathrm{~GB}(4)=830 \pm 2 \mathrm{~kJ} \mathrm{~mol}^{-1}$ (this work).

b $\mathrm{kJ} \mathrm{mol}^{-1}$.

c $\times 10^{-10} \mathrm{~cm}^{3}$ molecule ${ }^{-1} \mathrm{~s}^{-1}$.

yielding the $\mathrm{M}^{\cdot+}$ ions in the CI plasma are estimated to be endothermic in the present case, so no explanation can be given for this particular behaviour of 3 and 4. Furthermore the $\mathrm{MH}^{+}$ions of 3 and 4 decay easily by the loss of isobutene and by the formation of $t$-butyl cations $\mathrm{C}_{4} \mathrm{H}_{9}^{+}$, and the corresponding collision-induced dissociation (CID) processes occur after the transfer of $\mathrm{MH}^{+}$in the ICR cell before any collisional cooling.

The efficiencies for the deprotonation of 1 and 2 are large $(>50 \%)$ for exoergic reactions. They decrease steadily as $\Delta G_{\mathrm{r}}$ approaches zero (thermoneutrality) and become quite small $(<10 \%)$ for endoergic reactions. In each case, a sudden break in the efficiency of proton transfer occurs when $\Delta G_{\mathrm{r}}$ changes its sign. This is the typical behaviour of proton transfer reactions in 


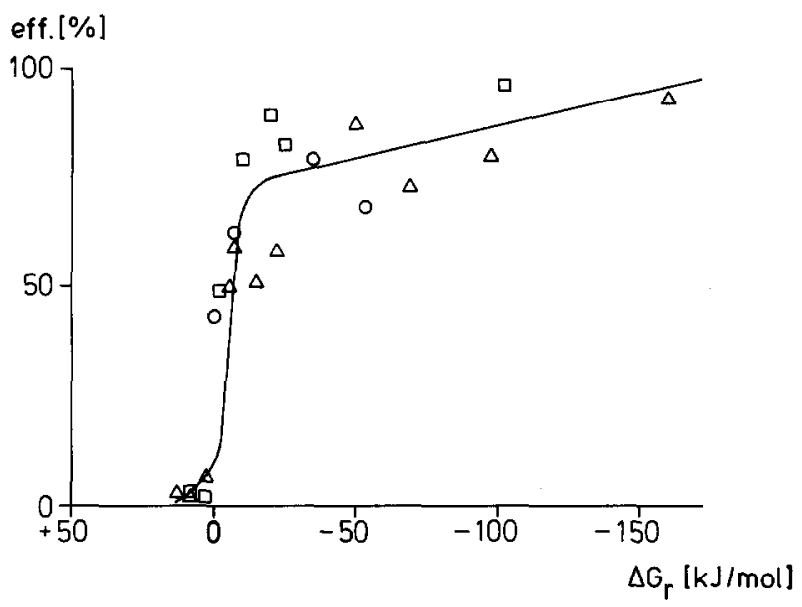

Fig. 1. Reaction efficiency vs. $\Delta G_{\mathrm{r}}$ for the protonation of $2(0), 3(\Delta)$ and $4(\square)$.

the absence of steric effects as expected for aromatic compounds without bulky substituents such as 1 and 2.

The results for the protonation of 2,3 and 4 are summarized in Table 2 . As in the case of the deprotonation of $\mathbf{2}$, the efficiency for the protonation of $\mathbf{2}$ is large ( $>50 \%$ ) for exoergic reactions and decreases steeply as soon as $\Delta G_{\mathrm{r}}$ changes its sign. Thus, 2 does not exhibit steric effects either for the protonation or for the deprotonation of $\mathrm{MH}^{+}$. Surprisingly, an identical behaviour is observed for the protonation of 3 (Table 2) in spite of the two bulky $t$-butyl substituents. The efficiency of protonation is about $50 \%$ even in the case of only weakly exoergic reactions and increases distinctly with increasing exoergicity. Eventually, it approaches nearly unit efficiency in the case of strongly exoergic reactions. The results obtained for 3 are confirmed by the measurements of the protonation rates of the even more sterically crowded 4. This compound is not volatile enough at $300 \mathrm{~K}$ to yield a pressure of neutral 4 in the ICR cell sufficient for the measurements of protonation rates. Hence, the inlet reservoir was heated to $400 \mathrm{~K}$. Since the temperature of both the ICR cell housing and the ICR cell was still at $300 \mathrm{~K}$, the temperature of the neutrals is not very well defined under these conditions, and the rates measured may deviate systematically from those obtained under the usual conditions. This has to be taken into account when comparing the absolute rates of protonation of 4 (Table 2) with those of 2 and 3. Nevertheless, the steep break in the efficiency at the border between exoergic and endoergic proton transfer reactions to 4 is clearly seen from the data in Table 2.

The efficiencies for the protonation of 2,3 and 4 are plotted versus the free reaction enthalpy $\Delta G_{\mathrm{r}}$ in Fig. 1 to show the identical behaviour of these 
alkylated benzenes of very different steric calibre. In all cases, the sudden decrease of the efficiency of protonation occurs at thermoneutrality $\left(\Delta G_{\mathrm{r}}= \pm 0 \mathrm{~kJ} \mathrm{~mol}^{-1}\right)$. Thus, the sterically crowded alkyl benzenes 3 and 4 show no extraordinary behaviour in proton transfer reactions compared with 2 , indicating the absence of steric effects on these proton transfer processes. These results are in clear contrast to those obtained by Houriet and Rolli [9a] for pyridines. Obviously the protonation of pyridine is sterically hindered by the screening of the lone pair localized in the ring plane by alkyl groups in the 2,6-positions [7,9]. In contrast, the electrophilic attack of the aromatic $\pi$-system by the protonated $\mathrm{n}$-base $\mathbf{B H}^{\prime}$ is not hindered even by bulky substituents at the ring. This indicates different mechanisms of the proton transfer to alkylated pyridines and alkylated benzenes.

Although the efficiencies of the proton transfer reactions of the alkylated benzenes 1-4 are quite large for weakly exoergic reactions, they are clearly below unit efficiency even for stronger exoergic reactions, in contrast to proton transfer to small molecules adding the proton to a lone pair [4]. Inefficient exothermic reactions have been observed for quite a number of different ion/molecule reactions $[6,7,19]$. An example, related to the transfer reactions studied here, is the proton transfer to delocalized negative ions [6]. Slow exothermic ion/molecule reactions are explained by the double well potential energy surface model developed by Brauman and co-workers [6,7], but may also be due to entropic effects as illustrated by Meot-Ner (Mautner) and Smith [9b]. According to thesc models, the reactions proceed by the formation of a long lived ion/molecule collision complex, which in the case of proton transfer most probably resembles a proton-bound species. The inefficiency of the reaction is due either to a central energy barrier corresponding to a "tight" transition state with a low density of states which separates the proton bound complex of the educts from the proton bound complex of the products or to a "freezing" of internal rotations in the components of the complex during the proton exchange within the complex. As a consequence, the rate of dissociation of the excited complex back to the reactants is larger than the rate of unimolecular rearrangement to the complex of the products. The double well potential model [6,7] has been used to explain slow proton transfer rates between substituted methyl benzenes [19] and the proton exchange between arenium ions and arenes [20]. In the case of a proton transfer to a benzene molecule the first potential energy minimum corresponds to a complex formed by the proton donor and the neutral benzene while the second one depicts a complex between the conjugated base of the proton donor and a benzenium ion. It is known from theoretical calculations [20-23] that the most stable structure of an alkylated benzenium ion corresponds to a $\sigma$-complex with the proton attached to the carbon atom para and/or ortho to the alkyl substituents. The direct transfer of the proton from the donor to 


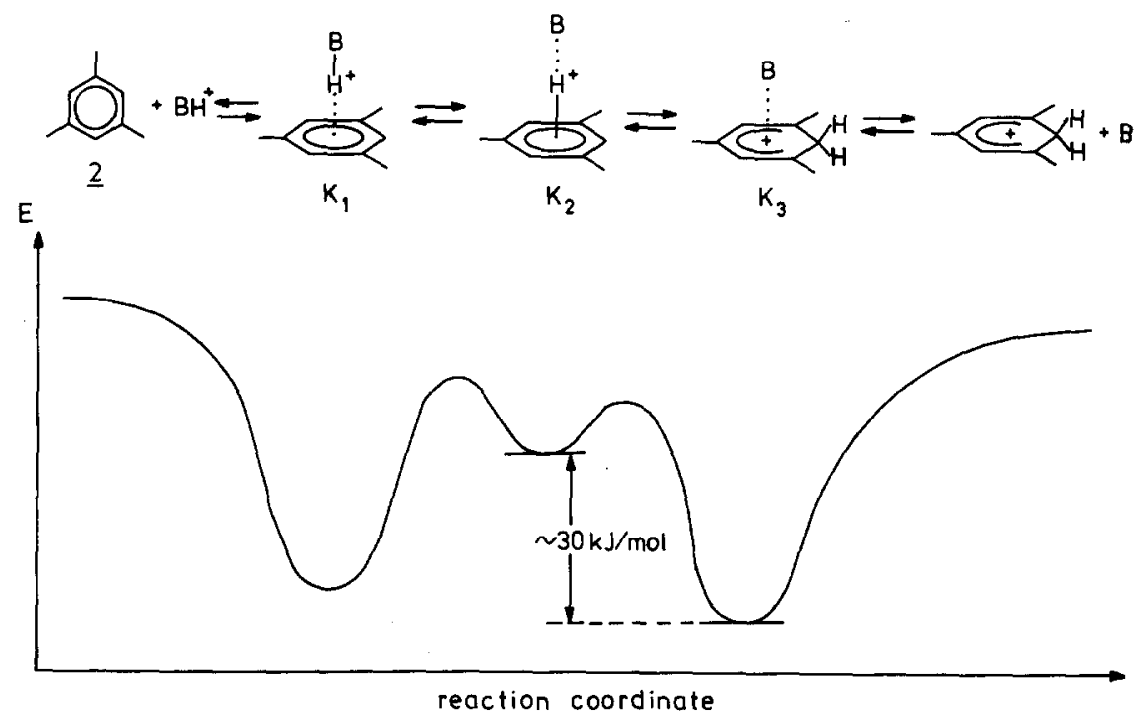

Fig. 2. Triple well potential for the proton transfer between an aromatic $\pi$-basc $M$ (herc 2) and an $n$-base $B$. $K_{1}$, collision complex; $K_{2}$, aromatic $\pi$-complex associated with $B ; K_{3}$, aromatic $\sigma$-complex associated with $\mathrm{B}$.

this carbon atom of the benzene ring requires a steric situation very similar to the proton transfer to the $\mathrm{N}$-atom of a pyridine molecule [9], although the line of transfer may deviate somewhat more from the plane of the aromatic ring in the former case. Nevertheless, bulky $t$-butyl groups at both sides of the point of attachment of the incoming proton should exert a similar steric hindrance to the proton transfer in both cases. However, these effects are only observed in the case of 2,6-di-( $t$-butyl)pyridines and not for sterically crowded benzenes 3 and 4 . This different behaviour shows that the steric effects discussed for the proton transfer to pyridines [9] are not important for benzenes, and the most obvious explanation for this difference would be a different steric orientation of pyridine and benzene respectively, within the reaction complex during the proton transfer.

To explain the low efficiencies as well as the absence of steric effects by bulky alkyl substituents in the case of alkylbenzenes, we suggest the triple well potential shown in Fig. 2 for the proton transfer between an aromatic $\pi$-base and an $\mathrm{n}$-base. According to this model, the protonation of the aromatic $\pi$-base $\mathrm{M}$ by the protonated $\mathrm{n}$-base $\mathrm{BH}^{+}$occurs by the following sequence of events. In the first step, $\mathrm{M}$ and $\mathrm{BH}^{+}$form a long lived collision complex $\mathrm{M} \cdots \mathrm{HB}^{+}\left(\mathrm{K}_{1}\right)$, in which the proton of $\mathrm{BH}^{+}$interacts with the $\pi$-electron cloud of the aromatic ring. In the next step, the proton transfer to the aromatic $\pi$-system results in an aromatic $\pi$-complex associated with $\mathbf{B}$, 
$[\mathrm{M} \cdots \mathrm{H} \cdots \mathrm{B}]^{+}\left(\mathrm{K}_{2}\right) . \mathrm{A} \pi$-complex has been assumed as a transition state with a calculated activation energy of $32 \mathrm{~kJ} \mathrm{~mol}^{-1}$ during the intramolecular proton transfer of an aromatic $\sigma$-complex [21,23]. However, other theoretical calculations showed that the $\pi$-complex is in fact an intermediate, not a saddle point $[20,22]$. Eventually, the $\pi$-complex $\mathrm{K}_{2}$ isomerizes to an aromatic $\sigma$-complex associated with the neutral base $\mathrm{B}, \mathrm{MH}^{+} \cdots \mathrm{B}\left(\mathrm{K}_{3}\right)$, which dissociates to $\mathrm{MH}^{+}$and $\mathrm{B}$. A $\sigma$-complex is calculated to be more stable by about $30 \mathrm{~kJ} \mathrm{~mol}^{-1}$ compared with the corresponding $\pi$-complex. With respect to the separated components, the stabilization energies of the complexes $\mathrm{K}_{1}, \mathrm{~K}_{2}$, and $\mathrm{K}_{3}$ in the potential minima (Fig. 2) can be estimated by an electrostatic force interaction model [24] to be about $40-100 \mathrm{~kJ} \mathrm{~mol}^{-1}$ depending on the polarizability and dipole moment of the neutral bases $\mathrm{M}$ and $\mathrm{B}$. This agrees reasonably with the enthalpy of dissociation of $46 \mathrm{~kJ} \mathrm{~mol}^{-1}$ reported for the complex $\mathrm{C}_{6} \mathrm{H}_{7}^{+} \cdot \mathrm{C}_{6} \mathrm{H}_{6}$, and indicates that in such proton bound aromatic dimers the binding is mostly electrostatic [25]. In this connection it is of interest that proton bound species were usually observed in our experiments for endoergic and weakly exoergic reactions: for example the weakly exoergic $\left(\Delta G_{\mathrm{r}}=-7 \mathrm{~kJ} / \mathrm{mol}^{-1}\right)$ protonation of 3 with $\mathrm{NH}_{4}^{+}$.

The relative heights of the potential energy barriers separating the three different complexes in Fig. 2 are unknown, and it is not possible to decide unambiguously whether the barrier of formation of the $\pi$-complex $\mathrm{K}_{2}$ or the barrier of isomerization to the $\sigma$-complex $\mathrm{K}_{3}$ is rate-determining. However, the fact that steric effects are not observed for the protonation of alkyl benzenes suggests that the aromatic $\pi$-complex $K_{2}$ plays a crucial role for the transfer of a proton to and from an aromatic system. In this mechanism of protonation the proton enters the aromatic system at the centre of the aromatic ring, and accordingly the proton donor is oriented above the centre of the aromatic $\pi$-electron cloud minimizing any steric hindrance by substituents at the rim of the aromatic ring. Once formed, the aromatic $\pi$-complex equilibrates quickly with the $\sigma$-complex before dissociation of the proton bound mixed dimer, a process known from the fast intraannular proton migrations ("proton ring walk") of arenium ions (for a recent review see ref. 26). Similarly, the internal energy gained by the collision complex formation between an aromatic $\sigma$-complex and an $\mathrm{n}$-base is used for isomerization into a $\pi$-complex, which then donates the proton to the n-base. Thus, for a proton transfer to and from an aromatic system the proton donor and the proton acceptor respectively, occupy a position above the centre of the aromatic ring which is not shielded by substituents at the aromatic ring. This structure of the transition state for a proton transfer is quite different to that for a proton transfer to the lone pair at the nitrogen atom of a pyridine, and explains the rather different response of heavily alkylated benzenes and pyridines to steric effects on protonation and deprotonation reactions. 


\section{ACKNOWLEDGEMENTS}

The FT-ICR spectrometer used during this work is a gift from the Deutsche Forschungsgemeinschaft. Financial assistance by the Deutsche Forschungsgemeinschaft is gratefully acknowledged. We are grateful for additional support by the Fonds der Chemischen Industrie.

\section{REFERENCES}

1 D.H. Aue and M.T. Bowers, Gas Phase Ion Chemistry, Vol. 2, Academic Press, New York, 1979.

2 S.A. McLuckey, D. Cameron and R.G. Cooks, J. Am. Chem. Soc., 103 (1981) 1313.

3 S.G. Lias, J.F. Liebman and R.D. Levin, J. Phys. Chem. Ref. Data, 13 (1984) 695.

4 D.K. Bohme, G.I. Mackay and H.I. Schiff, J. Chem. Phys., 73 (1980) 4976.

5 S.G. Lias, D.M. Shold and P. Ausloos, J. Am. Chem. Soc., 102 (1980) 2540.

6 W.E. Farneth and J.I. Brauman, J. Am. Chem. Soc., 98 (1976) 7891.

7 J.M. Jasinski and J.I. Brauman, J. Am. Chem. Soc., 102 (1980) 2906.

8 F. Cacace, Acc. Chem. Res., 21 (1988) 215.

9 (a) R. Houriet and E. Rolli, New J. Chem., 11 (1987) 221.

(b) M. Meot-Ner (Mautner) and J.C. Smith, J. Am. Chem. Soc., 113 (1991) 862.

10 P.M. Keehn and S.M. Rosenfeld, Cyclophanes I + II, Organic Chemistry, Vol. 45, Academic Press, New York, 1983.

11 P. Kofel, M. Allemann, H.P. Kellerhals and K.P. Wanczek, Int. J. Mass Spectrom. Ion Processes, 65 (1985) 97.

12 L.J. de Koning, R.H. Fokkens, F.A. Pinkse and N.M.M. Nibbering, Int. J. Mass Spectrom. Ion Processes, 77 (1987) 95.

13 M. Henchman, Ion-Molecule Reactions, Plenum Press, New York, 1972, Chapter 5.

14 J.E. Bartmess and R.M. Georgiadis, Vacuum, 33 (1983) 149.

15 K.J. Miller and J.A. Savchik, J. Am. Chem. Soc., 101 (1979) 7206.

16 W.J. Hehre, R.T. McIver, J. Pople and P.v.R. Schleyer, J. Am. Chem. Soc., 96 (1974) 7162.

17 T. Su and M.T. Bowers, Int. J. Mass Spectrom. Ion Phys., 12 (1973) 347.

18 S.J. Hazell, R.D. Bowen and K.R. Jennings, Org. Mass Spectrom., 23 (1988) 597.

19 J.A. Stone, X. Li and P.A. Turner, Can. J. Chem., 64 (1986) 2021.

20 D. Kuck, S. Ingemann, L.J. de Koning, H.-F. Grützmacher and N.M.M. Nibbering, Angew. Chem., Int. Ed. Engl., 24 (1985) 693.

21 T. Sordo, J. Bertran and E. Canadell, J. Chem. Soc., Perkin Trans. 2, (1976) 1486.

22 J.T. Gleghorn and F.W. McConkey, J. Chem. Soc., Perkin Trans. 2, (1976) 1078.

23 D. Heidrich and M. Grimmer, Int. J. Quantum Chem., 9 (1975) 923.

24 J.J. Grabowski, C.H. DePuy and V.M. Bierbaum, J. Am. Chem. Soc., 105 (1983) 2565.

25 M. Meot-Ner, P. Hamlet, E.P. Hunter and F.H. Field, J. Am. Chem. Soc., 100 (1978) 5466.

26 D. Kuck, Mass Spectrom. Rev., 9 (1990) 583. 